\title{
Analysis of the Adequacy of National Agricultural Policy in Addressing Entrepreneurial Education of Selected Agricultural Training Institutions in Zambia
}

\author{
Article by John Phiri, Emmy H Mbozi, Kalisto Kalimaposo \\ School of Education, University of Zambia \\ E-mail: johnphiri7@yahoo.com
}

\begin{abstract}
The study seeks to establish the adequacy of National Agricultural Policy in addressing entrepreneurial education of selected Agricultural Training Institutions in Zambia. A descriptive survey design was employed using a mixed methods approach but with greater focus on qualitative approach. Purposive random sampling procedure was used. Quantitative data was analysed using frequencies, percentages and tables while qualitative data was analysed thematically. Most of the respondents interviewed acknowledged that the current National Agricultural Policy did not adequately address entrepreneurial education in Agricultural Training Institutions. The National Agricultural Policy, both in terms of content and strategies did not appear to achieve the desired result of entrepreneurial education as they tended to be biased towards food security, fish, crop and livestock production compared to nurturing entrepreneurs. It showed fragmented sectorial strategies and policies which did not point to entrepreneurial education. A general lack of comprehensive institutional frameworks and Acts of Parliament to support and address the issues of entrepreneurial education in Agricultural Training Institutions was observed as a major constraint to job creation. The study concluded that entrepreneurial education in the National Agricultural Policy was inadequate. This research, therefore, recommended integration of entrepreneurial education in the National Agricultural Policy and enactment of appropriate strategic Acts of Parliament to support entrepreneurial education and decent job creation.
\end{abstract}

Keywords: Agricultural Training, Entrepreneurial Education, National Agricultural Policy

\section{Introduction}

Agriculture remains a priority sector in Zambia for attaining sustainable economic growth and employment creation. This is attributed to the country's vast natural resources such as huge tracks of arable land, water and a youthful population to support all forms of agricultural activities. Currently, it is estimated that over 80 percent of the Zambian population entirely depend on agricultural related activities for their livelihoods. Thus, this sector needs a lot of technical and professional support for its growth through training and human resource development. Therefore, human resource development in the sector has to be adequate and ready to take agriculture as a business in line with changing worldwide trends that are more sustainable and environmentally friendly (CSO,2005:2).

\section{Background}

Government, from the early 1990s, embarked on serious policy reforms that eventually affected the majority of sectors within a period of 10 years. The first draft of the National Agriculture Policy to guide and direct the development of the agricultural sector was formulated around that period. Consequently, the National Agriculture Policy (2004 to 2015) has since then provided a general framework in which the current agricultural development agenda in the country has taken place. The central thesis of this paper is to establish the adequacy of National Agricultural Policy in addressing entrepreneurial education in Agricultural Training Institutions. MACO (2004) records that Government's agenda for ensuring agricultural growth, poverty reduction and food security has been guided by the following agricultural development policies and strategies:(i) the National Agricultural Policy; (ii) the Vision 2030, and the National Development Plans such as the Sixth National Development Plan; iii) various specific policies and strategies guide development in the sector. The 
Ministry of Agriculture and Livestock has ten Agriculture Training Institutions namely; Natural Resources Development College, Zambia Institute of Animal Health, Popota Tobacco Training College, Zambia College of Agriculture (Mpika and Monze), Kasaka Fisheries, Cooperative College, Zambia Centre for Horticultural Training and Palabana Dairy Training Institute which support human resource development in the agricultural sector (GRZ, 2011).

\section{Literature review}

A considerable amount of literature has been published on entrepreneurial education. These studies show that entrepreneurial education is a better strategy to facilitate economic participation among young people (Kandemir and Acur, 2012). It is the most effective method for bridging the gap between technology, creating new enterprises and self-employment (Rahman and de Feis, 2009). A number of researchers have reported that supporting entrepreneurial education through adequate policies could achieve sustainable growth for business activities and self-employment. Entrepreneurial education in agricultural training institutions develops entrepreneurial capacities and mind sets in students (Consortium of Entrepreneurship Education. 2004). The foundation of any business is normally drawn mostly to entrepreneurs. Entrepreneurial education promotes skills for self-reliance (Kaplan and Warren, 2010). This calculated situation needs that those who practice it must be taught and well mentored. Sustainable economic growth in Agriculture depends on a strong National Agricultural Policy (Driver, 2012). Taylor and Richards, (1985) reviewed that human resource in training institutions should be equipped with appropriate entrepreneurial skills and knowledge in order for them to have a positive impact in society. Consequently, contents, theories, aims, objectives and pedagogies should be thoroughly inspected and mapped to entrepreneurial education (Ronan, 1995).

It has also been demonstrated that a strong National Agriculture Policy is fundamental to Entrepreneurial Education. It gives guidance on the formulation, alignment of objectives and contents of entrepreneurial education curriculum. It empowers management and training officers to build a vision for the future of their institutions. Management and training officers explore new opportunities and educational aspirations. Kreitner and Cassidy (2011) demonstrated that when a good policy framework is in place, it inspires and helps training authorities formulate sustainable entrepreneurial programmes. Financial resources are allocated to training institutions in accordance to given policy guidelines.

In the new global economy, entrepreneurial education has become a central issue in finding solutions to unemployment. It is a fast-growing area. One of the key factors explaining this phenomenon is the fact that wage employment, particularly in the public sector is no longer a guarantee. A longitudinal study of the Education Dilemma Policy Issues for Developing Countries in the 1980s by Simmons (1980) reports that entrepreneurial education can support learners develop and pursue entrepreneurial careers which may help them become successful self-employed people. It provides learners with the skills to take action and not to stay idle but make changes which will improve the environment within their community. Stevenson and Lundström, (2005) have argued that if entrepreneurial education is to have a single purpose, it should have a strong legal framework as well as articulated for improvement in the quality of life or, put in another way, the provision of life skills for graduates. (Cooper and Dunkelberg 1987) established that entrepreneurial education as a measure of policy, embraced by government, reduced mass poverty and unemployment. It entails a philosophy of self-reliance and productive environment, promoting new sets of attitudes in training institutions for the attainment of future challenges.

A broader perspective has been adopted by (Agi and Yellowe 2013). They demonstrate that National Agriculture Policy needs focus in tackling employment by reorganising small and medium scale enterprises. A good policy should help determine the way the production forces are organised. Gartner, (2001) found that the encouragement of good policies helps the dispersion and expansion of entrepreneurial education which broods economic activities and induce even development. Conversely, entrepreneurial education should be perceived as a catalyst to increase the rate of economic growth and create job opportunities

In the same vein, Meany (1994) in his book State Policy and the Development of Taiwan's Semiconductor Industry notes that training institutions must cultivate well-prepared students who 
should meet the intensive global competition. Equally, detailed examination of Policy and entrepreneurship by Lichtenstein, Lyons, and Kutzhanova (2004) showed that the concept of developing entrepreneurial education programmes should be guided by good policies. They note that human being's life is the implementation of every specific activity. Besides, if the object of training was to prepare individuals for their future careers, then the specific activities should help develop skills and knowledge that will enable students to successfully be self-employed. A good policy in place should be able to support this. They contended that well-functioning, appropriate and stable policy framework conditions, incentives and support formed the basis of a good entrepreneurial education (Charney and Libecup, 2000).

There has been an increased interest in entrepreneurial education within the education system and the society in general with an increase in courses, incubators and other activities oriented to promote the topic of entrepreneurial education (Kelly, 2010). Previous studies have reported that there are a variety of viewpoints directing the development of entrepreneurial education policies and a range of policy tools designated for countries in the world. It is likewise certain that consideration needs to be dedicated on the development of a framework that integrates policy measures and strategies to resolve challenges in various sectors of the economy. Arising from their research, Stevenson and Lundström (2005:60) established six policy priorities for entrepreneurial education policy framework namely:

1. Upholding entrepreneurship principles

2. Encouraging Entrepreneurial education in schools

3. Promotion of an atmosphere beneficial for start-ups enterprise: reducing barriers for entry to business, eliminating obstacles to industry and tax reforms,

4. Making available loans for new enterprises and seed capital

5. Delivering enterprise start-up support, such as incubators, networks and electronic business support;

6. Targeting underprivileged groups.

Gabr and Hoffman, (2006) used five drivers of entrepreneurial education to promote national agricultural policy namely Opportunities, Capital, Ability, Motivations, and Attitude. Panagiotou, (2008), has been exploring the development of entrepreneurial education frameworks for some time now. These framework measures are actually a set of policy tools to attain precise objectives in entrepreneurial education development. A policy framework is a collection of all policies to attain a set of objectives (UNCTAD, 2010).

Entrepreneurship and education policy are both roots of entrepreneurial education policy. In the context of the synopsis of research available on the connection of National Agricultural Policy and entrepreneurial education; Lauzikas and Cernikovaitè, (2011) observe that policy makers ought to narrow the perspective of the challenges involved in self-employment by concentrating on precise competence achievements in existing training institutions, enterprises and potential entrepreneurs. In the face of an increase in unemployment, nations should change the focus of their policies to facilitating new firm creation by equipping students with necessary entrepreneurial skills, knowledge and attitudes. They focused on four design principles that support formulation of entrepreneurial education policy framework namely; agreement with development partners who should contribute to a national entrepreneurial education strategy with extensive consultation between the government and representatives of all sectors of namely: business activity, education and financial institutions. Application of the policy guidelines by all line Ministries, as well as executing agencies which should include the private sector whose roles should be clearly defined and feedback mechanisms from lessons learnt with good guiding principles for support of entrepreneurial education should be well spelt (Gibb, 2002).

\section{Objective of the study}

The major objective of this study was to investigate the adequacy of National Agricultural Policy in addressing entrepreneurial education of selected Agricultural Training Institutions in Zambia. The study sought to answer the research question of how adequate entrepreneurial education was 
addressed in National Agricultural Policy. This study provides an exciting opportunity to advance our knowledge of the relation between entrepreneurial education and national agricultural Policy.

\section{Problem statement}

Research has revealed that entrepreneurial education has about ninety percent (90\%) bearing on all enterprises in growing economies and entrepreneurs provide fifty percent of jobs in such countries (Anho, 2013). There is an absence of documented proof of analysis of national agricultural policy on entrepreneurial education for Agricultural Training Institutions (Mayoux, 2001). The study sought to fill the knowledge gap on National Agricultural Policy and provision of entrepreneurial education for Agricultural Training Institutions in Zambia.

\section{Theoretical framework}

The study is hinged on rational and alignment model that best fits the specific needs of entrepreneurial education in Agricultural Training Institutions. The multi-step model was aimed to be logical and followed an orderly path from problem identification through to finding solutions (Porter, 2004). With this theory in view, the researchers conceptualised that policy was needed for entrepreneurial education. Porter argued that policy was an important factor that influenced training objectives and new enterprise growth. The theory revealed the significance of infrastructure, curriculum development, financial and human resources towards augmenting the entrepreneurial capacity to act on learned opportunities. Policy influences the way training authorities craft their curriculum and conduct their business. The theory emphasises the important role policy plays in facilitating effective and efficient formulation of contents to respond to objectives and desired outcomes in a society. It stresses policy guidelines as prerequisites for quality entrepreneurial education (Stacey, 2007).

\section{Methodology}

Generally, the research design integrated both qualitative and quantitative research methodologies. The main methods of data collection were questionnaires and interviews guides. The questionnaire had both closed and open-ended questions. The essence of combining data collection methodologies was to capture as much information from the respondents as possible. A total sample size of 63 was used. For the interviews, 23 respondents were interviewed comprising 10 Senior Officials from Ministry of Agriculture and Livestock at the level of Director or Assistant Director, 10 Principals or Vice Principals (Management of Agriculture Training Institutions), 5 former Principals or Vice Principals of Agricultural Training Institutions, 3 officials from Zambia National Farmers' Union, 2 officials from Technical Education Vocational and Entrepreneurship Training Authority and 3 officials from University of Zambia School of Agricultural Sciences. Questionnaires were administered to 40 Heads of Departments of Agricultural Training Institutions. Purposive random sampling procedure was used. Quantitative data was analysed using frequencies, percentages and tables. While qualitative data was analysed thematically. The approach to data collection was designed to attract and gain participation from Agricultural Training Institutions and other stakeholders' samples (Roscoe and Lang, 1975). Secondary data was collected through reports, documents and available literature at Ministry of Agriculture and Livestock (MAL) Web based information was also accessed.

\section{Findings and discussions}

In discussing the findings of this research, regarding National Agricultural Policy, the study revealed that there were a number of innovative activities in Zambia directly addressing entrepreneurship. For, example Citizenship Economic Empowerment Commission, Cooperatives, Commercial Banks and Zambia Development Agency that promoted small scale enterprises. The objective had also highlighted the views of various stakeholders on the adequacy of the National Agriculture Policy in addressing entrepreneurial education in Agricultural Training Institutions of Ministry of Agriculture and Livestock. The study revealed that the current National Agriculture Policy did not adequately address entrepreneurial education in Agricultural Training Institutions. The 
institutional frameworks in the National Agricultural Policy, for facilitating entrepreneurial education in Agriculture Training Institutions, were loosely developed. Although there were clear indications of collaborative work involving Government and entrepreneurs, entrepreneurial education was not mainstreamed into policy strategies. The National Agriculture Policy, both in terms of content and strategies did not appear to achieve the desired result of entrepreneurial education as they tended to be biased towards production compared to enterprise development. It was also observed that the present National Agriculture Policy was anchored on production and food security. The Policy review showed fragmented sectorial strategies and policies on entrepreneurial education. Along with emphasis on the growth of the agriculture sector, there is however, increasing concern over increased unemployment a general lack of comprehensive institutional frameworks and legislation to address the issues of entrepreneurial education in Agricultural Training Institutions were observed as major constraints in job creation. There was general awareness of the potentials and opportunities that entrepreneurial education in Agricultural Training Institutions could contribute to the Zambian economy. Nonetheless, there was a lack of clear approaches on how to exploit these potentials and opportunities in Agricultural Training Institutions which entrepreneurial education provided (FNDP, 2006).

\section{The national agricultural policy from 2004 to 2015}

\section{Tenets}

The National Agriculture Policy does not relate any of its contents on entrepreneurship to any of the ten (10) Agricultural Training Institutions under review, thus providing a weak link on entrepreneurial education for Agricultural Training Institutions. However, it has pointed to the Technical Education Vocational and Entrepreneurship Training Act, No. 13 of 1998 on the Legal Framework for Livestock production subsector as a viable subsector for employment creation.

\section{Institutional framework}

Agricultural training in the country is offered at various institutions namely the University of Zambia (Degree Level), Natural Resources Development College (Diploma Level), Mpika and Monze Agricultural Colleges (certificate and Diploma levels). Veterinary training is provided at the University of Zambia (Degree Level) and the Zambia Institute of Animal Health (Certificate Level). Others are Kalulushi, Chapula and Kasaka Farm Training Institutes and Palabana Livestock Development Trust and Farm Training Centers also provide short-term, demand driven courses. Some training institutions under the Ministry of Higher Education which also offer courses in Agricultural Mechanics. Co-operatives education and training is provided at the Co-operative College, Katete Centre of Marketing and Co-operatives and Kabulamwanda Co-operative Training Centre. Other training institutions such as the Natural Resources Development College (NRDC), Zambia College of Agriculture (ZCA-Mpika and Monze), the University of Zambia (UNZA) and Copperbelt University (CBU) would be encouraged to introduce the co-operatives concept in their training programmes (MACO, 2004). There is neither established legislation nor enactment of any Agricultural Training Act. This presents a weak link with other training institutions especially those with the mandate of providing entrepreneurship in the country.

After analysing the National Agriculture Policy, in order to get other people's perspectives, the research had to administer interviews and questionnaires for the purpose of triangulating.

Table 1. Effect of national agriculture policy on entrepreneurial education

\begin{tabular}{|l|l|l|l|l|l|}
\hline $\begin{array}{l}\text { Strongly } \\
\text { Agree }\end{array}$ & Agree & Disagree & $\begin{array}{l}\text { Strongly } \\
\text { Disagree }\end{array}$ & $\begin{array}{l}\text { Non- } \\
\text { Response }\end{array}$ & Total \\
\hline 0 & $8(20 \%)$ & $21(52.5 \%)$ & $11(27.5 \%)$ & 0 & $40(100 \%)$ \\
\hline
\end{tabular}

A total of $8(20 \%)$ of the respondents generally agreed with the assertion that the Agricultural Policy has had a positive effect on the entrepreneurial education in Agricultural Training Institutions in Zambia. Out of these, none of the respondents strongly agreed with this assertion. Only 8 (20\%) of the respondents agreed with this statement. On the contrary, a total of $32(80 \%)$ of the respondents 
generally disagreed with the assertion that Agricultural Policy has had a positive effect on entrepreneurial education in Agricultural Training Institutions in Zambia.

During the focus group discussions, it was widely held that entrepreneurial education had not been adequately addressed in the National Agricultural Policy. "Issues of entrepreneurship need to be mainstreamed in National Agricultural Policy if unemployment was to be resolved observed one respondent. But it appears that entrepreneurship is merely a lip service on the political agenda, in the end we are back to the same point in a circle. Policy makers assume too much that entrepreneurship would resolve itself", commented one respondent. "Entrepreneurship is a new phenomenon hence it is hardly understood. It calls for expert sensitisation. "That way job creation would be enhanced and government will certainly broaden its tax base because there is great potential for employment creation in the agriculture sector as exhibited by women and men who sell agro products in the streets" bemoaned some respondents. There has been a lot of uncertainty in undocumented policy pronouncements on self-employment by senior government officials. The quality of training offered in Agricultural Training Institutions was being questioned, due to high poverty levels and unemployment, which lacked proper policy guidelines from government. It was further confirmed by the fact that even the Department of Cooperatives which was under the Ministry of Agriculture had since been moved to the Ministry of Commerce, Trade and Industry hence defeating the fact that agricultural Cooperatives provide a large number of jobs for the masses, observed some respondents. That confirmed the fact that agriculture was merely production oriented, said one of the respondents.

It was reported that many training officers did not have entrepreneurship skills and there was no policy for them to undertake training in entrepreneurship related programmes. Some informants were dissatisfied with the quality of graduates produced in Agricultural Training Institutions. It was noted that quality of graduates was compromised because of lack of practical equipment and lack of policy directive to the development of trained human resource in agriculture and other related specialisations in Agricultural Training Institutions. The mismatch in terms of the Agricultural Training Institutions curricula and agricultural policy posed a lot of challenges for students when they graduated as they had to look for employment in the formal sector which was readily available. They had poor orientation whilst in the Colleges to stand on their own. Most of the respondents bemoaned the deteriorating standards in Agricultural Training Institutions caused by poor and sporadic funding which could not support the purchasing of practical equipment and other training materials to support Agricultural Training Institutions curricula.

Some respondents observed that a lack of commitment by policy makers in terms of entrepreneurial education coupled with poor and sporadic funding for income generating activities and production units in Agricultural Training Institutions led to deteriorating standards in teaching. It was extremely difficult to develop and implement programmes e.g. entrepreneurship in a situation where people did not perceive that there was a need for a specific policy guideline bemoaned some lecturers. "Government should ensure that policies are linked to the overall direction and goals of the agricultural training curriculum", reported some of the respondents. They mentioned that "the overall framework of the Agricultural policy needed to provide some strategic direction and that would be important in assessing the direction of Agricultural Training Institutions programmes and graduates in the field".

\section{Relevance of national agriculture policy in terms of entrepreneurial education}

Fifty-four $(85.7 \%)$ of the respondents expressed the need to strengthen the subject content and methodologies in Agricultural Training Institutions if quality had to be realised. It was noted that sporadic funding needed to be discouraged and that the Ministry of Agriculture and Livestock needed to design a suitable programme on entrepreneurship or Business management so as to achieve sustained relevance of job creation and self-employment. One of the respondents commented that good agricultural policy would contribute to the reduction of casualisation in Zambia. It was further reported that any changes in the Agricultural Training Institutions curriculum needed to be subjected to broader consultations with all stakeholders in the country. It was further reported that Agricultural policy should provide Agricultural Training Institutions direction and hold relevant stakeholders accountable for the outcomes of the curricula. 


\section{Utilisation of graduates from agricultural training institutions}

Forty-seven $(74.6 \%)$ of the respondents said the youth cohort was a vast resource that was significantly underutilised. It was important that support was targeted at groups with the greatest potential in particular those unemployed youths who already possessed professional skills and competencies in agriculture and other related programmes like fisheries and nutrition that could be transferred through coaching and mentorship. One of the respondents said it was essential for graduates from Agricultural Training Institutions were made aware of the important range of empowerment programmes that had been put in place by the government of Zambia. The government should have a deliberate policy to give resources to these graduates as a start-up business. When they got established, they could employ others and this could increase the tax base for the country, and reduce poverty.

Most of the respondents interviewed 55(87.3\%) observed that National Agriculture Policy focused on production, productivity of crops, fish and animals; but had not addressed entrepreneurial education in Agricultural Training Institutions to enable graduates to be self-employed or come up with start-up enterprises.

Most of the respondents strongly felt that entrepreneurial education needed to have been addressed thoroughly in the National Agriculture Policy because of high levels of poverty and youth unemployment in the country. Others noted that the National Agriculture Policy needed to address the real needs of Agricultural Training Institutions i.e. infrastructure development for practical training which was key to skills impartation and entrepreneurial education in order to have profitable ventures in the Agriculture Sector. "That would eventually increase the tax base for government revenue", commented one of the respondents. Most Agricultural Training Institutions training officers and some eminent retired Principals of Agricultural Training Institutions talked to noted that the Government had tried crop and animal marketing through various parastatal companies in a bid to provide employment since independence, until the liberalisation of the economy in 1991. However, "issues to do with entrepreneurial education have always been done unsystematically and there has never been a time when government had committed itself fully to mainstream entrepreneurial education through a National Agricultural Policy. Some senior officials talked to mentioned that the National Agriculture Policy has always been in draft form until 2004 when the first document was finalised" said some respondents. Some respondents felt that as long as the National Agriculture Policy did not address entrepreneurial education it would be very difficult for Agricultural Training Institutions to fully commit the curricula or any programme to entrepreneurial education. "A lack of policy guidelines on entrepreneurship is actually injurious to our youths who are the majority participants in trading of agricultural products who will always look to government for employment", said one of the respondents. Others observed that the National Agriculture Policy and Agricultural Training Institutions curricula would remain loosely linked in terms of preparing the students to be selfemployed if consideration was not made to mainstream entrepreneurial education in the National Agriculture Policy for Agricultural Training Institutions. It was reported that the students had challenges in finding employment and difficulties in starting up their own enterprises in society upon graduation as there appeared to be no support or policy guidelines on entrepreneurship.

The following were further observed:

1. At Agricultural Training Institutions the organizational structures, depicting how various positions relate and work with each other, were elaborate. These presented approved/established, proposed and at times improvised frames, but in all cases presented functional frames for management of the colleges;

2. There was evidence of participatory management systems in place at most colleges via technical committees addressing key areas of the colleges such as finance, procurement, admissions, examinations and others. The current Principals are dedicated and innovative who need to be given some latitude to run the colleges;

3. Funding for the Agricultural Training Institutions was mainly from government with donors' contribution being nominal. While most of the funds were from government, the disbursement was 'erratic', untimely and always below the budgeted amounts. This has 
made colleges find means of generating additional funds through Income Generating Activities (IGAs);

4. Amounts from such ventures were small and variable, but in all cases, they were recognised as important resource in meeting college obligations such as paying for maintenance, complementing student feeding, investing in development projects (IGAs) and paying staff allowances doing extra work. Institutions are well endowed with natural resources which can be turned into income generating ventures with proper business planning but as was noted most IGAs were done without any laid out business plans;

5. It was observed with concern that the diversity of programmes, as dictated by the mandates of the colleges, resulted in duplications as a popular programme were 'copied' by other colleges without due consideration of the capacity to deliver quality training. Issues of staffing and available infrastructure seemed to be given less weight than the financial benefits accruing from running the programmes.

\section{Conclusion}

This study provides a systematic assessment of entrepreneurial education and National Agricultural Policy as a means of contributing to self-employment. National Agricultural Policy, as a stand-alone policy may be impeded and will not be effective if the principle of entrepreneurial education is not considered. The study concludes with a description of how the National Agriculture Policy can help support Agricultural Training Institutions through the creation of an enterprise culture. It argues that, policies should be aligned to resolving gaps in employment with comprehensive entrepreneurial education strategies and supported by other relevant policies for example education policies (MOE, 1996). It suggests that a sound legal framework that allows integration of entrepreneurial education policy strategies should be crafted. The study has also demonstrated that there is need to mainstream entrepreneurial education in the National Agriculture Policy. Entrepreneurial education empowers students to build a vision for the future. It has also shown that there is need for government to open up its institutions for mentorship and grooming of new graduates in line with entrepreneurial education principles. This guidance could also be extended to other relevant industries. The suggested model is critical for the Government of Zambia to develop sustainable business enterprises and entrepreneurial culture. It also contends that a national agricultural policy promoting business novelty must correspondingly include instruments stimulating entrepreneurial education such as adequate qualified human resource, comprehensive curriculum development, adequate learning infrastructure and financial resources (Datta, 2011). It further argues that policies promoting agricultural training should be measured in the perspective of a 'holistic' entrepreneurial education policy framework. Entrepreneurial education results in formation of new firms based on novelty ideas. Firms of such kind have relatively high-growth potential for job creation (Bridges, 1995).

\section{Recommendations}

After the study had analysed the adequacy of National Agricultural Policy in addressing entrepreneurial education in selected Agricultural Training Institutions in Zambia using field information from key stakeholders and secondary data. It came up with the following key specific findings and recommendations:

There is need to re-look at the Agricultural Training Institutions starting from policy level. Appropriate Acts of Parliament to support this strategic intervention in all agricultural training institutions need to be enacted. It is not an acceptable status that prisons produce food to feed themselves when agricultural colleges fail to do so. A provision that should allow these institutions to have a commercial orientation component in their structure must be worked out. Finally, there has to be a mind-set change at Ministry of Agriculture and Livestock Head Quarters, with regard to training, if anything has to change at these institutions, which as alluded to above are an invaluable asset. 


\section{Based on the findings, the following recommendations were made}

1. The coordination of the Agricultural Training Institutions should be housed in a special Directorate that would oversee the entire training function on behalf of the Ministry of Agriculture and Livestock. This would improve the integrity of training as a process. This was alluded to in previous studies of the World Bank (World Bank (2011).

2. The training institutions should be rationalised on a discipline basis allowing for concentration of expertise. In this regard all fishery and aquaculture training must be at one institution. Kasaka Fisheries Training Institution should host such training at both Certificate and Diploma levels. Similar rationalization should be extended to animal science and health discipline with Zambia Institute of Animal Health hosting the training. Agricultural marketing and agri-business should be a 'branding' programme for Cooperative Colleges.

3. Katete Institute should be transformed into a Zambia College of Agriculture-Katete to cater for agro-ecological region II. In this regard it is strongly suggested that programmes at the three ZCA be harmonized but allow for 'branding' related to local agricultural production challenges.

4. Each college should establish business venture wings, whose objective would be to generate funds for college developmental agenda.

5. All training institutions should develop business plans with which they would use to solicit for financing from financial institutions. This would require a closer look at the policy related to Revolving Fund so as to extend or modify it to allow training institutes to borrow.

\section{Curriculum development and review}

1. The exercise of curriculum development and review has been going at different paces at the colleges and it is time this is coordinated and, therefore, it is recommended that there be a collegewide curriculum exercise to bring to pace the courses and programmes. The exercise should provide for harmonisation of programmes and be led by a single team. It is further suggested that the affiliation of colleges be coordinated by the proposed Directorate for quality assurance purposes. To ensure quality training it is suggested that an inspectorate be created to oversee quality assurance across all colleges.

\section{Human resource}

1. The qualifications of staff and the numbers need to be improved if the Agricultural Training Institutions are going to offer quality agricultural training. It is, therefore, recommended that a semi-reform process be undertaken for the Agricultural Training Institutions only to fill all posts with qualified staff. It is further recommended that a fast track training programme similar to the one the Ministry of Education has with UNZA School of Education be worked out to respond urgently to the need to upgrade the staff.

Further it is recommended that all training staff be trained in pedagogy as offered by Technical Education Vocational and Entrepreneurship Training Authority (TEVETA) affiliated training institutions.

\section{Infrastructure}

1. To ensure good support to training programmes the infrastructure must be improved since this is a mammoth task which requires deliberate study of the state of infrastructure. The current study has established that the state of the infrastructure is so bad that a detailed evaluation of the exact and extent of the deterioration of the infrastructure be done. It is, therefore, recommended that a separate study looking at the infrastructure, which should include structures, machinery and equipment be carried and this should look at options of replacement, repair and acquisition of new items.

2. There are infrastructure aspects that can be immediately addressed and these relate to information accessibility by students. It is recommended that all institutions be connected to internet and that an e-library be introduced at all institutes. 


\section{Management and Administration of Agricultural Training Institutes}

(a) It was noted that institutional policy changes recommended in the past has received little attention and their implications are still valid to date.

Revisited World Bank report recommendations on policy for possible implementation.

(b) It was observed that coordination of agricultural training was through two Agricultural Training Institutions Coordinators at Ministry of Agriculture and Livestock, but given the diverse of the disciplines encompassing animal health, horticulture, agricultural marketing to general agriculture, in the colleges such support cannot come from one office thus renders the support rather weak.

\section{References}

[1]. Agi U.K. and Yellowe N.A. (2013). Management Strategies for Regenerating Secondary Education for National Development and Self-Reliance. Journal of Teacher Perspective (JOTEP) 7(2).

[2]. Ajufo, B.I. (2013). Challenges of Youth Unemployment in Nigeria: Effective Career Guidance as a Panacea. An International Multidisciplinary Journal 7(1), 307-321.

[3]. Anho, J.E. (2013). Recreating the Management and Administration of Adult and Non-Formal Education Vis-àvis Entrepreneurship Education for Unemployment and Poverty Eradication. A paper presented at the Conference of Association of Nigeria Teachers (ASCONT), Enugu.

[4]. Bridges, W. (1995). Job shift. How to prosper in a workplace without jobs. London: Nicholas Braeley Publishing.

[5]. Charney, A. And Libecup, D.B. (2000). The impact of Entrepreneurship Education: An evaluation of the Berger Entrepreneurship Program at the University of Arizona, 1985-1999. Kansas City, M1. The Kauffman Centre for Entrepreneurial Leadership.

[6]. Consortium of Entrepreneurship Education. 2004. (Online) Available: http://www.entreed.org/_entre/lifelong.htm [Accessed 14 October 2015].

[7]. Cooper, C. A. and Dunkelberg, W. C. (1987). Entrepreneurial research: Old questions, new answers and methodological issues. American Journal of Small Business, 11(3): 11-23.

[8]. CSO, (2005) Ministry of Labour and Social Security Labour Force Survey Report, Labour Statistics Branch, CSO, Lusaka, Zambia

[9]. Datta, P.B. (2011). Exploring the evolution of entrepreneurial education and innovation: A case study from India. International Journal of Technology Management \& Sustainable Development, 10, 55-75. doi: tmsd.10.1.55_1.

[10]. Driver M. (2012) An Interview with Michael Porter: Social Entrepreneurship and the Transformation of Capitalism Academy of Management Learning and Education, 11 (2012), pp. 421-431

[11]. FNDP, (2006) Republic of Zambia Firth National Development Plan, December 2006, Lusaka

[12]. FSD Zambia (2009). Finances national survey 2009. Dynamics of Zambia's changing financial landscape. Lusaka, Zambia: FSD Zambia.

[13]. Gabr, H., and Hoffman, A. (2006). A general policy framework for entrepreneurship. FORA, Division for Research and Analysis, Copenhagen: Ministry of Business and Economic Affairs.

[14]. Gartner, W.B. (2001). "Is there an elephant in Entrepreneurship? Blind Assumptions in Theory Development. (Business Research)" Entrepreneurship Theory and Practice, Summer 2001

[15]. Gibb, A. (2002). In Pursuit of a New "Enterprise" and "Entrepreneurship" Paradigm for Learning: Creative Deconstruction, New Values, New Ways of Doing Things and New Combinations of Knowledge. International Journal of Management Review 4(3), 233-69.

[16]. Government of the Republic of Zambia. (2011). Sixth national development plan 2011 to 2015. Sustained economic growth and poverty reduction. Ministry of Finance and National Planning. (Online). Availablefrom: http://www.undp.org.zm/joomla/attachments/119_

[17]. Kandemir, D and Acur, N. (2012). 'Examining Proactive Strategic Decision-Making Flexibility in New Product Development', Journal of Product Innovation Management, 29, 4, pp. 608-622.

[18]. Kaplan, J. M. and Warren, A.C. (2010). Patterns of entrepreneurship management. $3^{\text {rd }}$ edition. New Jersey: John Wiley and sons.

[19]. Kelly M.J. (2010). The Origins and Development of Education in Zambia: from Pre-colonial Times of 1996: A Book of Notes and Readings -Image Publishers Limited, Lusaka.

[20]. Kreitner, R and Cassidy, C. (2011). Management. 12th ed. Mason, OH: South-Western Cengage 


\section{Texila International Journal of Management}

Special Edition Apr 2019

[21]. Lauzikas, M. and Cernikovaite, M.E. (2011). The Model of Social Innovations in the Emerging Market of Lithuania. Intelektinè ekonomika, (5 (3), 388-400.

[22]. Lichtenstein, G.A., T.S. Lyons, and N. Kutzhanova. (2004). Building Entrepreneurial Communities: The Appropriate Role of Enterprise Development Activities. Journal of the Community Development Society 35(1):5-24.

[23]. Mayoux, L. (2001). Jobs, Gender and Small Enterprises: Getting the Policy Environment Right. Geneva: ILO.

[24]. Meany, C. S. (1994) 'State Policy and the Development of Taiwan's Semiconductor Industry', in J. Aberbach et al., The Role of the State in Taiwan's Development (London: M. E. Sharpe).

[25]. Ministry of Agriculture and Cooperatives (2004). National Agricultural Policy 2004 to 2015. Government printers, Lusaka.

[26]. Ministry of Education (1996) Educating Our Future: National Policy on Education - Government Printers, Lusaka.

[27]. Panagiotou, G (2008) 'Conjoining prescriptive and descriptive approaches: Towards an integrative framework of decision-making. A conceptual note', Management Decision, 46, 4, pp. 553-564.

[28]. Porter, M.E. (2004). Competitive Strategy: Techniques for analysing industries and Competitors, The Free Press, New York.

[29]. Rahman, N, and de Feis, G (2009) 'Strategic decision-making: models and methods in the face of complexity and time pressure', Journal of General Management, 35, 2, pp. 43-59.

[30]. Ronan,N.J.(1995). Adult Learning Styles and Academic Performance. International Journal of University Adult Education, XXIV (1),27-36.

[31]. Roscoe, A.M and Lang, D. (1975): Follow up Methods, Questionnaire Length, and Market Differences in Mail Survey, Journal of Marketing, Vol.39. No 2, pp.20-35.

[32]. Stacey, R. D. (2007). Strategic management and organisational dynamics: the challenge of complexity to ways of thinking about organisations. 5. ed. Harlow: Financial Times.

[33]. Simmons, J, (ed,) (1980) The Education Dilemma Policy Issues for Developing Countries in the 1980s, Oxford: Pergamon Press.

[34]. Stevenson, L. and Lundström, A. (2005). Beyond the rhetoric: Defining entrepreneurship policy and its best practice components. Stockholm, Sweden: Swedish Foundation for Small Business Research.

[35]. Taylor, P.H. \& Richards, C. M. (1985): An Introduction to Curriculum Studies (London: NFER-Nelson).

[36]. UNCTAD (2010) World Investment Report 2000: Cross-border Mergers and Acquisitions (Geneva: UNCTAD).

[37]. World Bank (2011) World Development indicators (Washington, DC: International Bank for Reconstruction and Development). 